\title{
Effect of oxygen conditions on intracapsular development in two calyptraeid species with different modes of larval development
}

\author{
Antonio Brante ${ }^{1,2,5, *}$, Miriam Fernández ${ }^{1,2,5}$, Frédérique Viard ${ }^{3,4,5}$ \\ ${ }^{1}$ Departamento de Ecología Costera, Facultad de Ciencias, Universidad Católica de la Santísima Concepción, Casilla 297, \\ Concepción, Chile \\ ${ }^{2}$ Estación Costera de Investigaciones Marinas, Departamento de Ecología, Facultad de Ciencias Biológicas, \\ Pontificia Universidad Católica de Chile, Casilla 114-D, Santiago, Chile \\ ${ }^{3}$ UPMC Univ Paris 06, UMR 7144, Equipe Evolution et Génetique des Populations Marines, Station Biologique de Roscoff, \\ 29682 Roscoff, France \\ ${ }^{4}$ CNRS, UMR 7144, Station Biologique de Roscoff, 29682 Roscoff, France \\ ${ }^{5}$ International Associated Laboratory ‘Dispersal and Adaptation in Marine Species' (Station Biologique de Roscoff and \\ Center for Advanced Studies in Ecology and Biodiversity [CASEB])
}

\begin{abstract}
Oxygen availability in the aggregation of offspring has been shown to be a critical factor affecting the survival and development of embryos in aquatic systems. It is not yet known, however, to what extent the capacity to provide $\mathrm{O}_{2}$ to embryo aggregations may act on the time of parental protection (here encapsulation), ultimately determining indirect and direct embryonic development. We assessed $\mathrm{O}_{2}$ conditions during encapsulation, the factors determining those conditions, and the consequences on embryo survival in 2 gastropod species with contrasting developmental modes: Crepidula fornicata, an indirect developer, and Crepidula coquimbensis, a direct developer showing adelphophagy. Results showed that intracapsular $\mathrm{O}_{2}$ conditions decreased to almost hypoxic conditions throughout development in $C$. fornicata, in contrast to the oxygenated conditions observed in $C$. coquimbensis during the entire encapsulation period. These contrasting patterns between species were explained by: (1) differences in metabolic rate of the embryos, (2) differences in total metabolizing material per capsule throughout development, and (3) differences in wall thickness and rates of decay throughout development, which may affect $\mathrm{O}_{2}$ diffusion. Moreover, when the low $\mathrm{O}_{2}$ conditions observed at the end of the encapsulation period were maintained after hatching by artificially extending encapsulation for $3 \mathrm{~d}$, a dramatic negative effect on embryonic survival was observed in the indirect developer. In contrast, no effect on juvenile survival was observed in the direct developer. We suggest that hatching at intermediate stages of embryonic development in C. fornicata may be a response to increased $\mathrm{O}_{2}$ constraints during the encapsulated period.
\end{abstract}

KEY WORDS: Parental protection $\cdot$ Oxygen limitation $\cdot$ Developmental mode $\cdot$ Larvae $\cdot$ Crepidula Encapsulation

Resale or republication not permitted without written consent of the publisher

\section{INTRODUCTION}

The biological and physical factors that affect offspring development and survival, as well as their consequences on the evolution of offspring protection, have been extensively studied in terrestrial systems (Stearns 1992). Theoretical and empirical studies sup- port the hypothesis that high mortality risk during the early stages of development is one of the main biological factors favoring the evolution of offspring protection (Clutton-Brock 1991). Evidence from marine organisms suggests that mortality risk of unprotected embryos is higher than of protected embryos, regardless of the type of protection, which can range from 
aggregation in jelly masses or capsules to active guarding of the embryos by the parents (Pechenik 1979, Rumrill 1990). A wide range of physical factors can also influence offspring development and survival, determining the need for parental protection, affecting its extent, and ultimately driving its evolution (Williams 1966, Trivers 1972, Clutton-Brock 1991, Roff 2002). In aquatic systems, the low solubility and diffusion rate of $\mathrm{O}_{2}$ in water seem to be major constraints of parental protection through offspring aggregation (in amphibians: Crump 1996; in marine invertebrates: Booth 1995, Strathmann \& Strathmann 1995, Cohen \& Strathmann 1996, Dick et al. 1998, Lee \& Strathmann 1998, Fernández et al. 2000). Embryo aggregations of marine invertebrate species exhibit low $\mathrm{O}_{2}$ levels which negatively affect embryonic development and survival (Strathmann \& Strathmann 1982, Chaffee \& Strathmann 1984, Strathmann \& Chaffee 1984, Strathmann \& Strathmann 1995, Cancino et al. 2000). However, the consequences of reduced development and mortality risks during the protected phase on the optimal time of parental protection in aquatic systems are still poorly understood.

Offspring of species showing parental protection in the way of embryonic aggregation within jelly masses or capsules may complete part or the whole of its embryonic development within capsules. Offspring may hatch either as larvae (i.e. indirect development) or juveniles (i.e. direct development). There is some evidence that offspring of marine invertebrate species with direct development spend more time in the protected environment than those of species with indirect development. For example, data provided on calyptraeid marine gastropods in Collin (2003) suggest that direct developing species present longer intracapsular periods than species with indirect development (after correction by temperature). Theoretical models predict that the extent of protection time must be positively related to larval mortality risk in the external environment and negatively related to mortality in the protecting environment (Caswell 1981). Therefore, identifying the factors that affect embryonic survival is critical in understanding the evolution of developmental strategy, including the characteristics of parental protection in aquatic systems (Pechenik 1979). If $\mathrm{O}_{2}$ availability is a limiting factor inside aggregations, embryonic and/or parental responses are expected to arise in species showing direct developmental mode in order to increase $\mathrm{O}_{2}$ availability, reduce embryo mortality inside aggregations, and ultimately extend parental protection in comparison to species with indirect development.

The variety of mechanisms exhibited by marine invertebrates to increase $\mathrm{O}_{2}$ availability inside embryo aggregations highlights the relevance of $\mathrm{O}_{2}$ supply as a constraint in the evolution of parental protection in the ocean (e.g. Cohen \& Strathmann 1996, Baeza \& Fernández 2002). Marine species that provide passive protection (e.g. capsules, jelly masses) assure $\mathrm{O}_{2}$ provision by aggregating the embryos inside materials that enhance $\mathrm{O}_{2}$ diffusion (e.g. gel; Cohen \& Strathmann 1996, Lee \& Strathmann 1998). In some cases, females adjust the number of eggs (or the amount of metabolizing material) per aggregation according to environmental $\mathrm{O}_{2}$ conditions (Fernández et al. 2007). The degradation of the internal layer of the capsule wall by the embryos also enhances the $\mathrm{O}_{2}$ diffusion rate throughout development (Cronin \& Seymour 2000, Brante 2006). Females of some brooding species actively provide $\mathrm{O}_{2}$ to their offspring and adjust their brooding behaviors according to the $\mathrm{O}_{2}$ demand of the embryos (e.g. Baeza \& Fernández 2002, Fernández \& Brante 2003). However, it is unclear if the capacity to provide an oxygenated environment to the brood may affect the extent of parental protection in aquatic organisms and therefore explain the wide range of developmental patterns observed among marine invertebrates.

In this work, we tested the potential importance of $\mathrm{O}_{2}$ availability during encapsulated embryonic development in determining the time of hatching and thus the extent of parental protection. We used 2 marine gastropod species of the family Calyptraeidae; the indirect developer Crepidula fornicata and the direct developer C. coquimbensis, to assess $\mathrm{O}_{2}$ conditions during encapsulated development, the factors determining $\mathrm{O}_{2}$ conditions, and the consequences on embryo survival. The calyptraeids are good subjects for these studies because females of every species encapsulate and brood their embryos at least up to the veliger stage (Hoagland 1986, Collin 2003). If $\mathrm{O}_{2}$ availability for embryos constrains the duration of protection, it is expected that C. coquimbensis which exhibits direct development and extended protection (i.e. reaches more advanced developmental stages), would show maternal or embryonic responses that allow the maintenance of oxygenated conditions during development. On the other hand, the shorter protection time (hatching at earlier embryonic stages) observed in C. fornicata might be due to a lack of mechanisms that ensure an oxygenated protecting environment to the embryos throughout development.

Embryos of Crepidula fornicata and C. coquimbensis are packed in variable numbers in thin-walled capsules that do not show apical plugs. The capsules are attached to the substratum by a peduncle (Hoagland 1986, Brown \& Olivares 1996) and are incubated by the female between the propodium and neck (hereafter referred to as the incubation chamber). C. fornicata exhibits indirect development with an encapsula- 
tion period of $\sim 20 \mathrm{~d}$ (at $14{ }^{\circ} \mathrm{C}$; A. Brante pers. obs.), after which a veliger larva hatches (at ca. 400 to $450 \mu \mathrm{m}$ ). Metamorphosis of the pelagic larvae into benthic juveniles occur at a size of around $1000 \mu \mathrm{m}$. Females may incubate between 28 and 64 capsules, depending on body size, and each capsule may contain between 300 and 500 embryos. Capsular length ranges from 4.5 to $6.5 \mathrm{~mm}$. C. coquimbensis exhibits direct development and intracapsular cannibalism; juveniles hatch from the capsules (at ca. $1000 \mu \mathrm{m}$ ) after $\sim 30$ to $35 \mathrm{~d}$ of incubation at $14^{\circ} \mathrm{C}$ (A. Brante pers. obs.). Females incubate between 10 and 36 capsules, with capsular length between 2.5 and $4.0 \mathrm{~mm}$. Females deposit between 45 and 121 eggs capsule ${ }^{-1}$, however, only 10 to $20 \%$ of embryos survive due to cannibalism at the end of the encapsulated period.

To meet our goals, we first measured $\mathrm{O}_{2}$ conditions in the incubation chamber and inside the capsules throughout development. Then, we analyzed 3 factors that can affect $\mathrm{O}_{2}$ conditions during embryo development: (1) changes in standard metabolic rates of the embryos, (2) changes in the amount of metabolizing material, and (3) changes in the thickness of the capsule wall. Finally, we determined the consequences of extended protection under $\mathrm{O}_{2}$ conditions characteristic of each species on embryo survival.

\section{MATERIALS AND METHODS}

Individuals of Crepidula fornicata forming stacks were collected by SCUBA diving from Morlaix Bay (Brittany, France) in June 2005. This population was established in the 1960s following an accidental introduction associated with oyster aquaculture (Dupont et al. 2003). Specimens were transported to the Biological Station in Roscoff, France, where experiments were carried out. Females of C. coquimbensis were collected from the native population of Puerto Aldea (30 17' 32" S, 71 $\left.{ }^{\circ} 36^{\prime} 30^{\prime \prime} \mathrm{W}\right)$, Chile in March 2006, and transported to the Estación Costera de Investigaciones Marinas (ECIM) in Las Cruces, Chile, where experiments were conducted. In both cases, experimental animals were maintained in running seawater at $14^{\circ} \mathrm{C}$ (the mean sea temperature observed during the reproductive season [spring-summer] at both sites) for a few days before experiments were started.

Slightly different classifications of embryo stages were used for each species because Crepidula coquimbensis shows cannibalistic behavior and a different pattern of embryonic development than C. fornicata. For $C$. fornicata, 4 embryonic stages were identified: Stage I (from egg to cleaved embryos), Stage II: preveliger embryos, Stage III: early veliger, and Stage IV: late veliger (prior to hatching). For C. coquimbensis, the following categories were used: Stage I: from egg to cleaved embryos, Stage II: pre-veliger (embryos cannibalized are clearly distinguished inside the crop and no velum is observed), Stage III: veliger (velum is distinguished, shell is in calcification and crop is already observed), and Stage IV: pre-hatching juveniles (individuals have all the adult morphological characteristics). In some experiments, the 4 stages were compared while in others only Stages I and IV were considered.

Oxygen conditions in the incubation chamber and inside the capsules. To assess the $\mathrm{O}_{2}$ conditions that embryos of Crepidula fornicata and C. coquimbensis are exposed to during incubation time, $\mathrm{O}_{2}$ availability was monitored in the incubation chamber of females and inside the capsules.

Oxygen conditions in the incubation chamber: $\mathrm{O}_{2}$ availability (\% air saturation) was recorded in the incubation chamber of brooding and non-brooding (control) females using a Presens microptode (Microx I; tip diameter $\sim 100 \mu \mathrm{m}$ ) calibrated to 0 and $100 \%$ air saturation (solution saturated with $\mathrm{Na}_{2} \mathrm{SO}_{3}$ and aerated water, respectively), at constant temperature $\left(14^{\circ} \mathrm{C}\right)$. As individuals of Crepidula fornicata are attached such that one is on top of another forming a stack, a hole was drilled through the shell of the individual below the targeted female to gain access to the incubation chamber. Thus, the female second from the bottom of the stack was used for measurements in all experiments. Crepidula coquimbensis inhabits empty snail shells, so the incubation chamber was reached by drilling a hole through the hosting snail shell. The tip of the microoptode was inserted into the center of the female incubation chamber, which also corresponds to the middle of the capsule clump in brooding females. The microoptode was then fixed in position using modeling clay and super glue. The $\mathrm{O}_{2}$ level was recorded every $2 \mathrm{~s}$ for at least $2 \mathrm{~h}$. While measuring $\mathrm{O}_{2}$, females were maintained in plastic boxes with aerated seawater at constant temperature $\left(14^{\circ} \mathrm{C}\right)$. After recording $\mathrm{O}_{2}$ conditions in the incubation chamber, the capsules were counted and the developmental stage of embryos was assessed using a binocular microscope. For this experiment, only females incubating capsules with embryos at Stages I and IV were compared because of the difficulties in attaining a reasonable sample size without prior knowledge of development stages of the embryos. A total of 5 replicates for each female condition (non-brooding females and females incubating embryos at Stages I and IV) and for each species were used. It is important to note that average female size was not significantly different among female conditions $(C$. fornicata: mean $=91.7 \mathrm{~mm}( \pm 11.6 \mathrm{SE})$, $F_{2,12}=2.03, \mathrm{p}=0.17 ;$ C. coquimbensis: mean $=25.8 \mathrm{~mm}$ $\left.( \pm 3.8 \mathrm{SE}), F_{2,12}=0.01, \mathrm{p}=0.98\right)$. No differences within 
species were found in the mean number of capsules per clump of females incubating capsules with embryos at different embryonic stages, which is a prerequisite for comparing $\mathrm{O}_{2}$ conditions in the incubation chamber $\left(C\right.$. fornicata: mean $=47.6( \pm 5.9 \mathrm{SE}), F_{1,8}=$ $0.16, \mathrm{p}=0.69 ;$ C. coquimbensis: mean $=23.1( \pm 4.4 \mathrm{SE})$, $F_{1,8}=0.59, \mathrm{p}=0.42$ ). Prior to the measurements of $\mathrm{O}_{2}$ condition, hypoxic conditions were defined by identifying the break point where the \% air saturation affects metabolic rate of embryos. This was accomplished by comparing the metabolic rates of encapsulated embryos between 3 categories of $\%$ air saturation $(100-80,80-60$ and $60-40 \%)$ for both species and for embryos at early and late embryonic developmental stages. According to these comparisons, we defined hypoxic conditions at air saturation levels below $60 \%$ for both species and developmental stages. Then, the $\%$ of time that capsules containing embryos at Stages I and IV were exposed to hypoxic conditions $(<60 \%$ air saturation) was estimated for C. fornicata and C. Coquimbensis. A 2-way ANOVA was used to determine the significance of differences in the mean \% of time that hypoxic conditions were detected in the incubation chamber between female conditions (nonbrooding females and females incubating capsules with embryos at Stages I and IV) and between species. No transformation of the data was needed. The a posteriori Newman-Keuls ( $\mathrm{N}-\mathrm{K})$ test was used to test for differences between treatments.

Intracapsular oxygen conditions: To evaluate intracapsular $\mathrm{O}_{2}$ conditions during embryo development, intracapsular air saturation (\%) was monitored at different embryonic stages in both species using microoptodes. Calibration of the microoptode was performed as described above. Prior to $\mathrm{O}_{2}$ measurements, capsules were carefully removed from mothers and kept in oxygenated seawater $\left(100 \%\right.$ air saturation, $\left.14^{\circ} \mathrm{C}\right)$ for $10 \mathrm{~min}$. Then, the tip of the microoptode was carefully inserted through the wall using a binocular microscope and positioned in the center of each capsule. Once the microoptode was positioned, the capsules were maintained immersed in aerated seawater at constant temperature $\left(14^{\circ} \mathrm{C}\right)$. At least $1 \mathrm{~h}$ of $\mathrm{O}_{2}$ recording was conducted for each capsule. In this case, 4 developmental stages (I, II, III and IV) were studied for each species. For each embryo stage and species, a minimum of 6 capsules were measured. For data analysis, only the second $1 / 2 \mathrm{~h}$ of $\mathrm{O}_{2}$ recording was used to avoid potential effects of manipulation. Mean $\mathrm{O}_{2}$ availability, estimated as \% air saturation, was compared between species and among embryo stages using a 2-way ANOVA. A posteriori $\mathrm{N}-\mathrm{K}$ tests were used to determine significance of differences between treatments.

Changes in capsule wall thickness throughout embryo development. To assess changes in the capsule wall through the development of embryos, which could affect $\mathrm{O}_{2}$ diffusion (Brante 2006), the thickness of the capsule wall for capsules containing embryos of Crepidula fornicata and C. coquimbensis at Stages I and IV were measured under transmission electron microscopy. For both species, 4 capsules containing embryos at both developmental stages and from different females were fixed and stored in $3 \%$ glutaraldehyde with $0.1 \mathrm{M}$ sodium cacodylate buffer at $\mathrm{pH} 7.2$ for later analyses. For electron microscopy, samples were washed overnight in a buffer solution at $4^{\circ} \mathrm{C}$ followed by fixation with $1 \%$ osmium tetroxide for 90 min and dying in a block with $1 \%$ uranyl acetate for $60 \mathrm{~min}$. The samples were dehydrated with acetone, preembedded in 1:1 epon:acetone and finally embedded in epoxic resin (Embed 812). After $24 \mathrm{~h}$ of polymerization, transversal ultrafine sections of capsule walls were prepared using a Sorvall MT-5000 ultramicrotome and dyed with $4 \%$ uranyl acetate in methanol for $2 \mathrm{~min}$, followed by lead citrate for $5 \mathrm{~min}$. Samples were studied under a Philips Tecnai 12 transmission electron microscope at $80 \mathrm{kV}$. Sections from the mid portion of the capsules were photographed and used to measure wall thickness. Mean wall thickness was compared between species and embryo stages using 2-way ANOVA. A posteriori N-K tests were used to determine significance of differences between treatments.

Oxygen consumption and embryo dry weight throughout embryo development. To identify the main factors affecting intracapsular $\mathrm{O}_{2}$ availability, total $\mathrm{O}_{2}$ consumption of the embryos and total metabolizing material in each capsule were measured for both species. Oxygen electrodes (Eschweiler M200) were used to measure embryo $\mathrm{O}_{2}$ consumption. The electrodes were calibrated to 0 and $100 \%$ air saturation (solution saturated with $\mathrm{Na}_{2} \mathrm{SO}_{3}$ and aerated water, respectively). Before measurements, each capsule was carefully cleaned with a paintbrush under filtered, UV-sterilized seawater $\left(14^{\circ} \mathrm{C}\right)$ to reduce the bacterial charge. Capsules were acclimated for $1 \mathrm{~h}$ before experiments in filtered, UV-sterilized seawater at $100 \%$ air saturation. Oxygen consumption was measured at $100 \%$ air saturation in both species to unmask potential differences in the standardized metabolic rate of embryos between species and avoid bias due to differences in the $\mathrm{O}_{2}$ condition inside incubation chambers. Oxygen depletion was monitored continuously until $80 \%$ air saturation was reached, in a double-wall closed micro-chamber filled with $2 \mathrm{ml}$ of stirred and filtered, UV-sterilized seawater. In each trial, 1 capsule containing embryos was measured at constant seawater temperature $\left(14^{\circ} \mathrm{C}\right)$. Oxygen consumption was measured in embryos inside capsules because the embryos of both species, and especially embryos of C. fornicata, show a higher swimming activity outside 
capsules than inside (pers. obs.) which may overestimate $\mathrm{O}_{2}$ consumption. At the end of the experiments, capsules were dissected and developmental stage was determined under the binocular microscope. Finally, embryos without capsule were filtered in glass fiber filters and cleaned with formic acid to extract salt content. Filters and embryos were dried in an oven for $24 \mathrm{~h}$ and weighed on a digital balance. Total dry weight of embryos was estimated by subtracting the weight of the filter from the total weight (embryo + filter). Estimation of total dry weight (mg) of the embryos per capsule allowed us to estimate embryonic metabolic rate as well as changes in the amount of metabolizing material through developmental time. Oxygen consumption was estimated in $\mu \mathrm{mol} \mathrm{O}_{2} \mathrm{mg}^{-1} \mathrm{~min}^{-1}$. In this case, 4 embryo stages (I, II, III and IV) were used. Ten capsules per embryo stage, removed from different females, were measured. Two-way ANOVA was used to compare mean $\mathrm{O}_{2}$ consumption and total dry weight between species and among embryo stages. A posteriori N-K tests were used to test for differences between treatments. Total dry weight data were log-transformed to meet ANOVA assumptions.

Larval/juvenile survival under artificial extension of the parental protection time. Measurements of intracapsular $\mathrm{O}_{2}$ availability ( $\%$ air saturation) through embryo development of both species determined the $\mathrm{O}_{2}$ condition that embryos experienced at the final stages of encapsulated development (see 'Results'). Using this information, we evaluated the consequences of maintaining protection, under $\mathrm{O}_{2}$ conditions characteristic of late developmental stages, on embryonic survival in these species, artificially extending the encapsulation period for $3 \mathrm{~d}$. During the first hour after hatching, the larvae (Crepidula fornicata) and juveniles (C. coquimbensis) were transferred to artificial incubation chambers maintained at the intracapsular $\mathrm{O}_{2}$ condition observed at Stage IV in each species (15 and $55 \%$ of air saturation, respectively). Seawater was changed each day to prevent bacterial contamination. The incubation chambers were maintained with filtered, UV-sterilized seawater at $14^{\circ} \mathrm{C}$. Air saturation level was maintained by bubbling nitrogen through an airstone, and monitored with a Presens microptode (Microx I). pH was monitored with colorfixed indicator sticks and maintained between $\mathrm{pH} 7$ and 8. Daily, the number of larvae or juveniles showing active behavior (surviving larvae and juveniles) was counted under a binocular microscope. A second set of larvae (C. fornicata) and juveniles (C. coquimbensis) were cultivated at $100 \%$ air saturation (constant aeration), during the same time period, as a control. Ten replicates per treatment and species were carried out. For C. fornicata, 200 larvae were cultivated in each replicate while 20 juveniles were cultivated for $C$. Co- quimbensis, to maintain similar amounts of metabolizing material in both experiments ( $2 \mathrm{mg})$. The larvae used for the experiments were obtained from a pool of larvae collected from 5 capsules, from 5 different females. Since $\mathrm{O}_{2}$ conditions differed between species, separate $t$-tests were performed for each species to compare larval survival rate after $3 \mathrm{~d}$ of incubation between $\mathrm{O}_{2}$ conditions. Data were arcsine-transformed prior to the analysis.

\section{RESULTS}

\section{Oxygen conditions in the incubation chamber and inside the capsules}

\section{Oxygen conditions in the incubation chamber}

A significant interaction between species and female condition was observed $\left(F_{2,24}=8.9, p=0.0012\right.$; Fig. 1$)$, since air saturation in the incubation chamber decreased faster through incubation time in Crepidula fornicata than in C. coquimbensis. The proportion of time that the incubation chamber showed hypoxic conditions increased as embryos developed in both species (N-K test: $\mathrm{p}<0.05)$. For any given stage, the incubation chamber of $C$. fornicata showed a higher frequency of hypoxic conditions than C. coquimbensis (N-K test: $\mathrm{p}<0.05$ ). It is notable that similar levels of hypoxia in the incubation chamber were found between females brooding early stage embryos (Stage I) of C. fornicata and late stage embryos (Stage IV) of C. coquimbensis (N-K test: $\mathrm{p}>0.05)$.

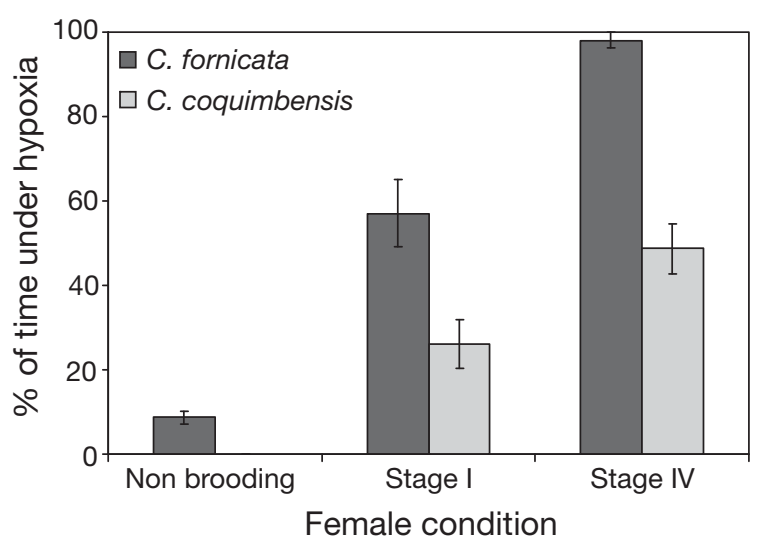

Fig. 1. Crepidula fornicata and C. coquimbensis. Average relative amount of time (\%) under hypoxic conditions $(<60 \%$ air saturation) in incubation chambers for the 3 female conditions studied (non-brooding females and brooding females incubating embryos at Stage I and IV of development). The incubation chamber of non-brooding females of C. coquimbensis did not show hypoxia during the experiment. Error bars indicate $\pm 1 \mathrm{SE}$ 
Intracapsular oxygen condition

The mean $\%$ air saturation inside the capsules decreased from 64 to $5 \%$ as embryo development progressed in Crepidula fornicata and from 87 to $53 \%$ in C. coquimbensis (Fig. 2). The interaction term of the ANOVA was significant, indicating clear differences in the rate of decrease in air saturation through development between species $\left(F_{3,63}=51.1, \mathrm{p}<0.0001\right)$. A posteriori analysis showed that the mean \% air saturation inside capsules significantly decreased from Stage I to Stage IV for C. fornicata. Although $\mathrm{O}_{2}$ conditions (\% air saturation) also decreased as embryos developed in C. COquimbensis, significant differences were detected only between capsules containing early (I and II) and late (III and IV) embryo stages (N-K test: $p<0.05)$. No differences were detected between capsules containing embryos in Stages I and II and between III and IV (N-K test: $\mathrm{p}>0.05)$. It is interesting that mean intracapsular $\mathrm{O}_{2}$ conditions in C. coquimbensis are comparable to those observed in C. fornicata only during early development. In fact, no differences in mean intracapsular $\mathrm{O}_{2}$ conditions were detected between capsules containing embryos of $C$. fornicata at Stage I and capsules of $C$. coquimbensis containing embryos in any stage of development (N-K test: $\mathrm{p}>0.05)$.

\section{Changes in capsule wall thickness throughout development}

Transmission electron microscopy gave indications about the structural organization of the capsule wall of Crepidula fornicata and C. coquimbensis. Capsules of

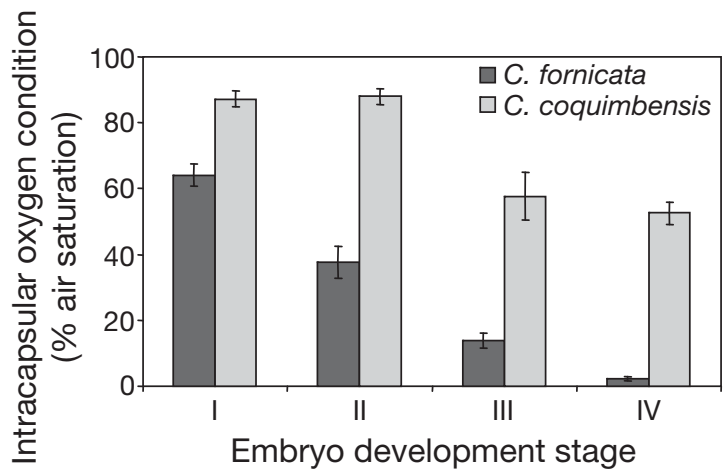

Fig. 2. Crepidula fornicata and C. coquimbensis. Mean air saturation (\%) observed inside capsules for different embryo developmental stages (I, II, III and IV). Error bars indicate \pm 1 SE
C. fornicata
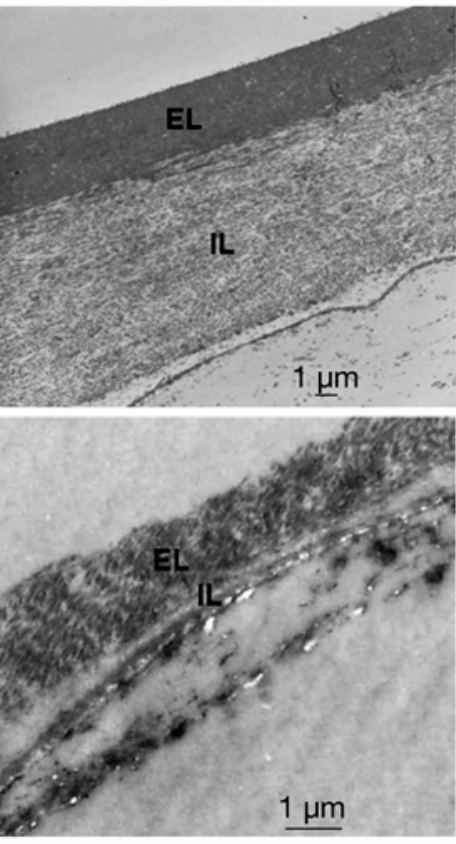

Fig. 3. Crepidula fornicata and C. coquimbensis. Transverse sections of the wall of capsules containing embryos at Stages I and IV. Sections were observed under transmission electron microscopy. EL = External layer, IL = Internal layer

both species showed similar morphology and were composed of 2 layers of different structure and thickness (Fig. 3). Parallel fibers run along the external layer forming a denser structure than the internal layer. The internal layer is in direct contact with the intracapsular fluid; it is wider and exhibits a lower optical density with only few longitudinal fibers immersed in the matrix. The visible structural organization of the external layer was maintained throughout embryonic development. When total \% of wall reduction was compared, a significant interaction between species and developmental stages was observed (ANOVA: $F_{1,12}=79.8, \mathrm{p}<0.0001$; Fig. 4). The interaction was significant because the rate of decrease in capsule wall thickness differed between species. C. fornicata showed a greater reduction in capsule wall thickness between early and late embryo development (83\%) than C. coquimbensis (51\%). Capsules of C. fornicata showed thicker walls than capsules of C. coquimbensis during early embryo development, while the inverse pattern was observed in capsules containing embryos at Stage IV (Fig. 4). In both cases, only the internal layer thickness decreased. It is important to note that we report the \% of decrease in capsule wall thickness throughout development. Since encapsulated development is shorter in C. fornicata than in C. coquimbensis, the difference in daily rate of reduction in capsule wall between species is even stronger. 


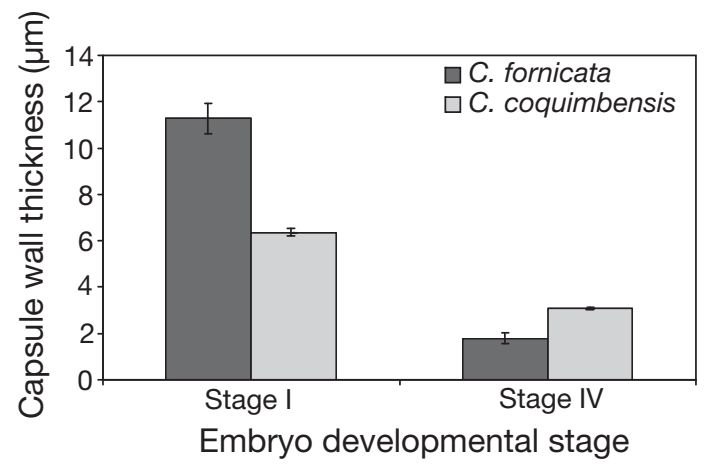

Fig. 4. Crepidula fornicata and C. coquimbensis. Mean thickness $(\mu \mathrm{m})$ of the wall of capsules containing embryos at Stages I and IV. Error bars indicate $\pm 1 \mathrm{SE}$

\section{Oxygen consumption and embryo dry weight throughout development}

A significant interaction between factors was detected in embryo $\mathrm{O}_{2}$ consumption $\left(F_{3,74}=3.36, \mathrm{p}=0.02\right)$. This was explained because $\mathrm{O}_{2}$ consumption increased at a faster rate throughout development in Crepidula fornicata than in C. coquimbensis (Fig. 5a). Oxygen consumption of $C$. fornicata embryos increased significantly from Stage II to IV (N-K test: $\mathrm{p}<0.05)$. No significant difference was detected between embryos at Stages I and II (N-K test: $\mathrm{p}>0.05)$. In contrast, $\mathrm{O}_{2}$ consumption of $C$. coquimbensis embryos significantly increased from Stage II to III (N-K test: $\mathrm{p}<0.05)$ but no differences were observed between Stages I and II and between Stages III and IV (N-K test: $p>0.05)$. Except for Stage I embryos which did not show significant dif-

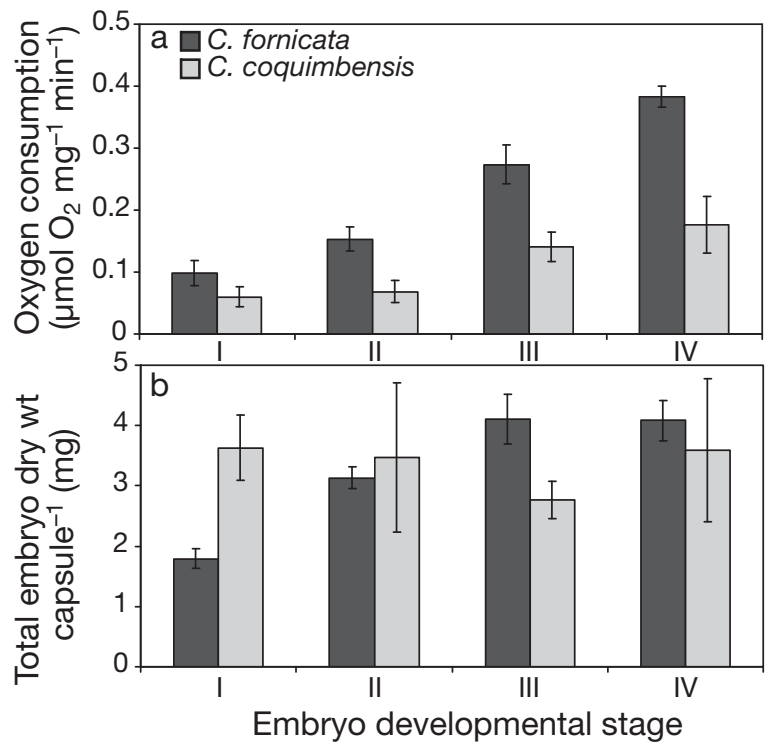

Fig. 5. Crepidula fornicata and C. coquimbensis. (a) Oxygen consumption ( $\mu \mathrm{mol} \mathrm{O}_{2} \mathrm{mg}^{-1} \mathrm{~min}^{-1}$ ), and (b) total dry weight of embryos per capsule at Stages I, II, III and IV. Error bars indicate $\pm 1 \mathrm{SE}$ ferences between species ( $\mathrm{N}-\mathrm{K}$ test: $\mathrm{p}>0.05), \mathrm{O}_{2}$ consumption recorded for embryos of $C$. coquimbensis was almost half the consumption of $C$. fornicata embryos (Fig. 5a).

A significant interaction in the ANOVA also precluded us from testing the effect of species and embryo stages on mean dry weight of embryos per capsule $\left(F_{3,74}=2.91, \mathrm{p}=0.02\right.$, Fig. $\left.5 b\right)$. The interaction was significant because total dry weight of embryos of $C$. fornicata significantly increased from Stage I to III (N-K test: $\mathrm{p}<0.05$ ) while total embryo dry weight capsule $\mathrm{e}^{-1}$ of C. coquimbensis was constant throughout embryo development (N-K test: $\mathrm{p}>0.05)$.

\section{Larval/juvenile survival under artificial extension of the parental protection time}

Significant differences in larval survival of Crepidula fornicata were observed between treatments after $3 \mathrm{~d}$ of artificially extending intracapsular $\mathrm{O}_{2}$ conditions ( $t$-test: $t=27.7, \mathrm{df}=18, \mathrm{p}<0.0001$; Fig. 6). Larval survival of $C$. fornicata decreased to $11.3 \%$ under $15 \%$ air saturation in contrast to the $98.5 \%$ survival in the control treatment $(100 \%$ air saturation). Crepidula coquimbensis showed a different pattern. Survival of hatching individuals did not differ between the experimental (55\% air saturation) and the control treatment $(100 \%$ air saturation; $t$-test: $t=1.5, \mathrm{df}=18, \mathrm{p}=0.15$; Fig. 6).

\section{DISCUSSION}

Our comparative analysis of $\mathrm{O}_{2}$ conditions for embryo development showed clear differences between the 2 calyptraeid species with different developmental modes. While $\mathrm{O}_{2}$ levels inside capsules and in the incu-

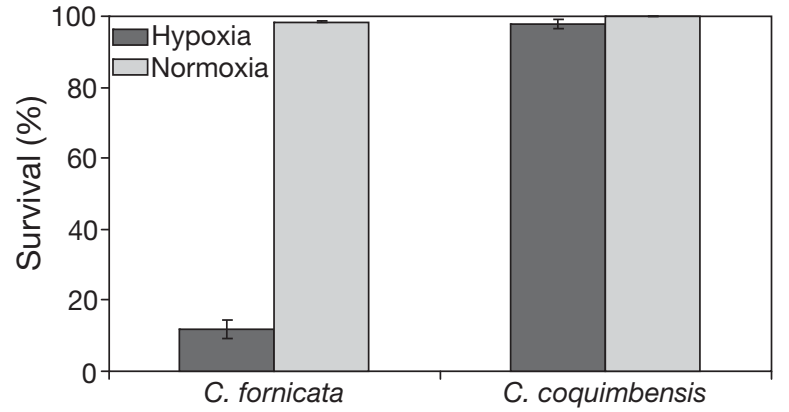

Fig. 6. Crepidula fornicata and C. coquimbensis. Larval survival (\%) measured after $3 \mathrm{~d}$ of incubation in artificial capsules under hypoxia and normoxia (control). Hypoxia treatments were $15 \%$ air saturation for $C$. fornicata and $55 \%$ for C. coquimbensis, which were the $\mathrm{O}_{2}$ conditions in the incubation chamber at the end of embryonic development. Error bars indicate $\pm 1 \mathrm{SE}$ 
bation chamber remained higher most of the time in the direct developer Crepidula coquimbensis, constant deterioration of $\mathrm{O}_{2}$ conditions reaching almost anoxic levels inside capsules towards the later stages, was observed in the indirect developer C. fornicata. The differences in $\mathrm{O}_{2}$ conditions between species can be explained by a combination of 3 different factors: (1) differences in embryo $\mathrm{O}_{2}$ consumption and in the rate of increase in $\mathrm{O}_{2}$ demand with developmental time, (2) differences in the total amount of metabolizing material per capsule throughout development, and (3) initial differences in capsule wall thickness and in the degradation rate of the capsule wall throughout development. The dramatic effect of artificially extending protection on larval survival allows us to hypothesize that the persistence of an intermediate freeliving stage in $C$. fornicata may be a response to limitations in $\mathrm{O}_{2}$ availability inside capsules which may reduce protection time and promote hatching.

Oxygen availability during embryo development is one of the most important physical factors constraining embryo packing and parental protection through embryo aggregation in aquatic systems (Booth 1995, Strathmann \& Strathmann 1995, Cohen \& Strathmann 1996, Fernández et al. 2000, Baeza \& Fernández 2002, Brante et al. 2003). In this study, we showed that encapsulated embryos are exposed to brief (Crepidula coquimbensis) or continuous periods (C. fornicata) of hypoxia, especially during late development. In comparison with other marine gastropods, the indirect developer $C$. fornicata showed one of the most dramatic intracapsular depletions of $\mathrm{O}_{2}$ availability during embryonic development reported in the literature, reaching almost complete anoxia before hatching (Cancino et al. 2000, Lardies \& Fernández 2002, Brante 2006). It is notable that the lowest $\mathrm{O}_{2}$ levels at late embryonic stages were reported in capsule aggregations of another species with an indirect development strategy, the gastropod Tritonia diomedea ( 5\% air saturation; Moran \& Woods 2007). The indirect developer Chorus giganteus shows intracapsular $\mathrm{O}_{2}$ levels lower than $40 \%$ air saturation at late embryo stages (Cancino et al. 2000). In contrast, the few studies evaluating $\mathrm{O}_{2}$ conditions inside capsules in species exhibiting direct development show smaller changes in this variable through developmental time, and generally higher \% air saturation. Intracapsular $\mathrm{O}_{2}$ availability in the direct developer Acanthina monodon was high (>50\% air saturation) at all developmental stages (Lardies \& Fernández 2002). We found a similar pattern in capsules of the direct developer C. coquimbensis in which $\mathrm{O}_{2}$ availability never dropped below $50 \%$ air saturation. We did not account for the potential effect of the accumulation of metabolites on embryos. However, previous studies suggest that $\mathrm{O}_{2}$ availability, rather than metabolic wastes, is the main factor limiting embryo development in other marine gastropods (Strathmann \& Strathmann 1995, Moran \& Woods 2007). Our observations and the literature strongly suggest that $\mathrm{O}_{2}$ conditions inside aggregations may influence the extension of parental protection through encapsulation.

The reduction in intracapsular $\mathrm{O}_{2}$ availability was the result of the combination of an increase in the metabolic rate of embryos in both species and an increase in embryo weight (metabolizing material) in the indirect developer Crepidula fornicata over time. Changes in the metabolic rate throughout embryonic development are commonly observed in other species with either developmental mode (Parry 1978, Brante 2006, Moran \& Woods 2007). This phenomenon may be explained by: (1) the increase in metabolic expenditure required by complex cellular processes, such as development of different embryo organs and systems, (2) the increase in the energetic cost of basal maintenance, and (3) the increase in the swimming activity of embryos with time. Our results show that the standard metabolic rate of embryos of the direct developer C. coquimbensis is half that of the indirect developer C. fornicata at intermediate and late embryonic stages (II, III and IV). One of the factors explaining the differences in $\mathrm{O}_{2}$ consumption between species is the fact that $C$. fornicata embryos show higher swimming activity than embryos of $C$. coquimbensis (A. Brante pers. obs.). The differences in the swimming activity between embryos of both species may be explained by the well-developed velum and high ciliary activity of C. fornicata embryos, which facilitate feeding and swimming during the planktonic phase (Klinzing \& Pechenik 2000). In contrast, embryos of C. coquimbensis have a reduced velum allowing only limited movements. Other morphological traits in embryos of C. coquimbensis are better developed to enhance cannibalistic behavior, such as an elastic oral aperture and a kind of crop that can store cannibalized embryos. Comparing the metabolic rate of embryos between the indirect developers Chorus giganteus, C. concholepas (J. Cancino unpubl. data.) and Tritonia diomedea (Moran \& Woods 2007), and the direct developer Acanthina monodon (M. Fernández unpubl. data), we observed that the direct developer shows almost 1/10 of the metabolic rate observed in the indirect developers. We think that the higher $\mathrm{O}_{2}$ consumption of the embryos in indirect developers could deplete the intracapsular $\mathrm{O}_{2}$ more rapidly than in the direct developer. Although more studies are needed to explore the generality of the pattern and the adaptive value of this phenomenon, it is likely that embryos of direct developers show lower metabolic rates which could help to extend protection time. 
There is a possibility that the actual value of $\mathrm{O}_{2}$ consumption of embryos estimated in this experiment, especially in pre-hatching embryos of Crepidula fornicata, may show some bias given that measurements were performed in normoxic conditions and not in natural $\mathrm{O}_{2}$ conditions (hypoxia); this is because metabolic rate may decrease in response to hypoxia. However, it is likely that the relative response in $\mathrm{O}_{2}$ consumption which is higher in C. fornicata, and the general pattern observed (i.e. an increase towards late stages for both species), should not change. Nonetheless, we do not discard the hypothesis that a reduction in the $\mathrm{O}_{2}$ demand of embryos exposed to hypoxic condition may be a response to extreme $\mathrm{O}_{2}$ conditions inside capsules, reducing the depletion rate of $\mathrm{O}_{2}$ through developmental time. But, it is clear that any reduction in the metabolic rate of embryos of $C$. fornicata at late stage is not enough to maintain a long-term viability of life in almost anoxic conditions as our experiments suggest.

The second factor that may explain the changes in intracapsular $\mathrm{O}_{2}$ conditions in the indirect developer Crepidula fornicata is the increase of metabolizing material (mg of total embryo weight) inside capsules over time. Given that the embryos of this species do not have yolk or other nutrition sources supplied by the parents, it is possible that the increase in the total embryo dry weight was due to consumption of intracapsular material. Previous studies have shown that this behavior is common among encapsulated embryos of gastropod species (De Mahieu et al. 1974, Rivest 1992, Rivest \& Strathmann 1995, Moran 1999, Ojeda \& Chaparro 2004). For example, encapsulated embryos of the indirect developer $C$. fecunda, and of indirect and direct developer species of the genus Littorina have provided evidence of consumption of capsular material by embryos (Moran 1999, Ojeda \& Chaparro 2004). In addition in C. fecunda, changes in the intracapsular protein content was related to capsule wall degradation (Ojeda \& Chaparro 2004). Our observations under the transmission electron microscope provided evidence that thickness of the internal layer of the capsule wall decreases with developmental time in both $C$. fornicata and C. coquimbensis. Experimental studies using fluorescent albumen and isotopes showed that encapsulated embryos of the indirect developer C. fornicata may incorporate dissolved organic material from the surrounding medium (A. Brante pers. obs.). In contrast to C. fornicata, the metabolizing material inside capsules of the direct developer C. coquimbensis did not change over the developmental time period. Although degradation of the capsule wall was also evident in this species, experimental observations indicate that the embryos have low capacity for incorporating dissolved organic material (A. Brante pers. obs). Thus, the temporal pattern ob- served in the total embryo dry weight of $C$. coquimbensis may be explained by the cannibalistic behavior of embryos (adelphophagy). Embryos of some encapsulating species have the potential to self-regulate the number of siblings (or metabolizing material) per capsule, an adjustment that seems to be related not only to nutritional needs but also to the need to regulate $\mathrm{O}_{2}$ availability (Lardies \& Fernández 2002). Like C. Coquimbensis, the direct developer gastropod Acanthina monodon shows adelphophagy, cannibalizing siblings during intracapsular development. Moreover, the rate of cannibalism increases as $\mathrm{O}_{2}$ conditions deteriorate (lower $\mathrm{O}_{2}$ partial pressure; Lardies \& Fernández 2002). In the direct developer $C$. dilatata, more nurse eggs are eaten per embryo when a higher number of eggs per capsule are laid (Chaparro et al. 1999). Although this kind of response may pay an important cost in terms of embryonic survival (mortality by cannibalism), it may be critical to maintaining the amount of metabolizing material, and consequently reduce or delay the effect of $\mathrm{O}_{2}$ depletion, allowing embryos to reach more advanced developmental stages.

The reduction in thickness of the capsule wall with time may not only have a nutritional implication, but additional benefits for both indirect and direct developer encapsulated species. Capsule wall thickness of the indirect developer gastropod Fusitritron oregonensis decreases through embryo development (Brante 2006). These changes have positive effects on intracapsular $\mathrm{O}_{2}$ conditions, increasing the $\mathrm{O}_{2}$ conductance of the capsule wall (Brante 2006). Similar changes in physical parameters of the capsule wall have been reported in other aquatic encapsulating species such as cephalopods (Cronin \& Seymour 2000) and amphibians (Seymour et al. 1991, Seymour \& Bradford 1995, Mills et al. 2001). It is likely that Crepidula fornicata and C. COquimbensis display a similar strategy to reduce the effects of the increase in embryo $\mathrm{O}_{2}$ demand with developmental time. However, in contrast to the results observed in F. oregonensis, it is clear that the reduction in thickness of the capsule wall does not compensate for the deterioration of the intracapsular $\mathrm{O}_{2}$ conditions in C. fornicata, but may help to delay the deterioration in $\mathrm{O}_{2}$ conditions. A further benefit of a decrease in capsule wall thickness is hatching facilitation. In other species of encapsulating gastropods, hatching of larvae or juveniles usually occurs through the apical plug or the suture (Sullivan \& Maugel 1984, D'Asaro 1988, Hawkins \& Hutchinson 1988, Garrido \& Gallardo 1993). However, as capsules of C. fornicata and C. coquimbensis do not have any of these structures, hatching would be facilitated by internal degradation of the capsule wall by embryo activity (Ojeda \& Chaparro 2004).

In contrast to these embryonic strategies, parental behavior can contribute to the provision of appropriate 
$\mathrm{O}_{2}$ conditions (Hess 1993, Dick et al. 1998, Naylor et al. 1999, Thiel 1999, Fernández et al. 2000, Baeza \& Fernández 2002). In fact, females of brooding crabs actively provide $\mathrm{O}_{2}$ to their egg masses according to the metabolic demand of embryos (Wear 1974, Wheatly 1981, Fernández et al. 2000, Brante et al. 2003). However, given that the center of the clump of capsules of the indirect developer Crepidula fornicata exhibited a predominantly hypoxic condition, it seems that brooding females of this species can not provide an oxygenated environment to their progeny. The incubation chamber of direct developer $C$. coquimbensis showed higher levels of $\mathrm{O}_{2}$ availability at all developmental stages than that of $C$. fornicata. It is probable that these differences are related not only to the lower $\mathrm{O}_{2}$ demand of embryos of C. coquimbensis but also to maternal behavior performed to improve $\mathrm{O}_{2}$ conditions inside the incubation chamber, which were not evaluated in this study. This problem must be addressed in future work to determine whether maternal ventilatory behavior plays a role in intracapsular $\mathrm{O}_{2}$ conditions.

The experiment which simulated an extension of the protection time in both species indirectly sheds light on the role of $\mathrm{O}_{2}$ in limiting the evolution of optimal protection time. The low $\mathrm{O}_{2}$ levels observed in capsules of the indirect developer Crepidula fornicata containing embryos at late stages can significantly increase the risk of embryo mortality if protection time increases. This was evident in the high larval mortality observed in this species after $3 \mathrm{~d}$ of incubation in hypoxic conditions in comparison with the low mortality exhibited by juveniles of the direct developer C. coquimbensis over the same time period. It appears that the combination of encapsulation and poor embryonic and female responses in maintaining proper $\mathrm{O}_{2}$ conditions inside capsules could play a critical role in shaping parental protection time, particularly in C. fornicata. More studies on marine invertebrates exhibiting parental protection strategies and with different embryonic developmental modes could improve our understanding of the main factors shaping the evolution of parental care in the ocean.

Acknowledgements. We thank A. Munizaga who helped with microscopic analyses. We also thank the divers L. Leveque, G. De Liège, W. Thomas, and S. Mery from 'Service Mer \& Observation' of SBR (France), and R. Calderon and F. Véliz from ECIM (Chile) for sampling. C. Murphy and M. Lee improved the English version of this manuscript. J. Pechenik and 3 anonymous reviewers are also thanked for their helpful comments. A.B. was supported through a CONICYT doctoral scholarship (AT 24050187), Ministère de la Recherche and DRI (Direction Relation Internationale) CNRS. Travel and stay for F.V. and A.B. were supported by ECOS funds. F.V. acknowledges the CNRS for financial support to the Laboratoire International Associé DIAMS. M.F. thanks Fondecyt (project \#1060489). A.B. also thanks the IDEA Wild Foundation

\section{LITERATURE CITED}

Baeza JA, Fernández M (2002) Active brood care in Cancer setosus (Crustacea: Decapoda): the relationship between female behaviour, embryo oxygen consumption, and the cost of brooding. Funct Ecol 16:241-251

> Booth D (1995) Oxygen availability and embryonic development in sand snail egg masses. J Exp Biol 198:241-247

> Brante A (2006) An alternative mechanism to reduce intracapsular hypoxia in ovicapsules of Fusitriton oregonensis (Gastropoda). Mar Biol 149:269-274

> Brante A, Fernández M, Eckerle L, Mark F, Pörtner HO, Arntz W (2003) Reproductive investment in the crab Cancer setosus along a latitudinal cline: egg production, embryo losses and embryo ventilation. Mar Ecol Prog Ser 251: 221-232

Brown DI, Olivares CA (1996) A new species of Crepidula (Mollusca: Mesogastropoda: Calyptraeidae) from Chile: additional characters for the identification of eastern Pacific planar Crepidula group. J Nat Hist 30:1443-1458

Cancino JM, Gallardo CS, Torres F, Leiva G, Navarro JM (2000) Effects of sessile Protozoa in intracapsular oxygen tension and embryonic shell calcification in the muricid Chorus giganteus. Mar Ecol Prog Ser 200:141-148

> Caswell H (1981) The evolution of 'mixed' life histories in marine invertebrates and elsewhere. Am Nat 117:529-536

Chaffee C, Strathmann RR (1984) Constraints on egg masses. I. Retarded development within thick egg masses. Biol Bull 84:73-83

Chaparro OR, Oyarzun RF, Vergara AM, Thompson RJ (1999) Energy investment in nurse eggs and egg capsules in Crepidula dilatata Lamarck (Gastropoda, Calyptraeidae) and its influence on the hatching size of the juvenile. J Exp Mar Biol Ecol 232:261-274

Clutton-Brock TH (1991) The evolution of parental care. Princeton University Press, Princeton, NJ

Cohen C, Strathmann R (1996) Embryos at the edge of tolerance: effects of environment and structure of egg masses on supply of oxygen to embryos. Biol Bull 190:8-15

Collin RR (2003) Worldwide patterns in mode of development in calyptraeid gastropods. Mar Ecol Prog Ser 247:103-122

Cronin ER, Seymour RS (2000) Respiration of the eggs of the giant cuttlefish Sepia apama. Mar Biol 136:863-870

Crump ML (1996) Parental care among the Amphibia. In: Rosenblatt JS, Snowdon CT (eds) Advances in the study of behavior. Elsevier, Amsterdam, 25:109-144

D'Asaro CN (1988) Micromorphology of neogastropod egg capsules. Nautilus 102:134-148

De Mahieu GC, Penchaszadeh PE, Casal AB (1974) Algunos aspectos de las variaciones de proteínas y aminoácidos libres totales del líquido intracapsular en relación al desarrollo embrionario en Adelomelon brasiliana (Lamarck, 1811) (Gastropoda, Prosobranchia, Volutidae). Cah Biol Mar 15:215-227

> Dick JT, Faloon SE, Elwood RW (1998) Active brood care in an amphipod: influences of embryonic development, temperature and oxygen. Anim Behav 56:663-672

Dupont L, Jollivet D, Viard F (2003) High genetic diversity and ephemeral drift effects in a successful introduced mollusk (Crepidula fornicata: Gastropoda). Mar Ecol Prog Ser 253:183-195

Fernández M, Brante A (2003) Brood care in brachyuran crabs: the effect of oxygen provision on reproductive costs. Rev Chil Hist Nat 76:157-168

Fernández M, Bock C, Pörtner HO (2000) The cost of being a caring mother: the ignored factor in the reproduction of marine invertebrates. Ecol Lett 3:487-494 
Fernández M, Calderón R, Cancino JM, Jeno K (2007) Effect of temperature on the development of encapsulated embryos of Concholepas concholepas along a latitudinal cline. Mar Ecol Prog Ser 348:229-237

Garrido O, Gallardo CS (1993) Ultraestructura de la capsula ovifera de Concholepas concholepas (Bruguiere, 1789) (Gastropoda: Muricidae). Rev Biol Mar 28:191-201

Hawkins LE, Hutchinson S (1988) Egg capsule structure and hatching mechanism of Ocenebra erinacea (L) (Prosobranchia: Muricidae). J Exp Mar Biol Ecol 119:269-283

Hess HC (1993) The evolution of parental care in brooding spirorbid polychaetes: the effect of scaling constraints. Am Nat 141:577-596

Hoagland KE (1986) Patterns of encapsulation and brooding in the Calyptraeidae (Prosobranchia: Mesogastropoda). Am Malacol Bull 4:173-183

Klinzing MSE, Pechenik JA (2000) Evaluating whether velar lobe size indicates food limitation among larvae of the marine gastropod Crepidula fornicata. J Exp Mar Biol Ecol 252:255-279

Lardies MA, Fernández M (2002) Effect of oxygen availability in determining clutch size in Acanthina monodon. Mar Ecol Prog Ser 239:139-146

Lee CE, Strathmann RR (1998) Scaling of gelatinous clutches: effects of sibling competition for oxygen on clutch size and parental investment per offspring. Am Nat 151:293-300

Mills NE, Barnhart MC, Semlitsch RD (2001) Effects of hypoxia on egg capsule conductance in Ambystoma (Class Amphibia, Order Caudata). J Exp Biol 204:3747-3753

Moran AL (1999) Intracapsular feeding by embryos of the gastropod genus Littorina. Biol Bull 196:229-244

Moran AL, Woods HA (2007) Oxygen in egg masses: interactive effects of temperature, age, and egg-mass morphology on oxygen supply to embryos. J Exp Biol 210:722-731

Naylor JK, Taylor EW, Bennett DB (1999) Oxygen uptake of developing eggs of Cancer pagurus (Crustacea: Decapoda: Cancridae) and consequent behaviour of ovigerous females. J Mar Biol Assoc UK 79:305-315

> Ojeda JA, Chaparro OR (2004) Morphological, gravimetric, and biochemical changes in Crepidula fecunda (Gastropoda: Calyptraeidae) egg capsule walls during embryonic development. Mar Biol 144:263-269

Parry GD (1978) Effects of growth and temperature acclimation on metabolic rate in the limpet Cellana tramoserica (Gastropoda: Patellidae). J Anim Ecol 47:351-368

Pechenik JA (1979) Role of encapsulation in invertebrate life histories. Am Nat 114:859-870

Rivest BR (1992) Studies on the structure and function of the

Editorial responsibility: Inna Sokolova,

Charlotte, North Carolina, USA larval kidney complex of prosobranch gastropods. Biol Bull 182:305-325

Rivest BR, Strathmann RR (1995) Uptake of protein by an independently evolved transitory cell complex in encapsulated embryos of neritoidean gastropods. In: Wilson WH, Strickler SA, Shin GL (eds) Reproduction and development of marine invertebrates. John Hopkins University Press, Baltimore, MD, p 166-176

Roff DA (2002) Life history evolution. Sinauer Associates, Sunderland, MA

Rumrill SS (1990) Natural mortality of marine invertebrate larvae. Ophelia 323:163-198

Seymour RS, Bradford DF (1995) Respiration of amphibian eggs. Physiol Zool 68:1-25

Seymour RS, Geiser F, Bradford DF (1991) Gas conductance of the jelly capsule of terrestrial frog eggs correlates with embryonic stage, not metabolic demand or ambient $\mathrm{PO}_{2}$. Physiol Zool 68:206-222

Stearns SC (1992) The evolution of life histories. Oxford University Press, New York

Strathmann RR, Chaffee C (1984) Constraints on egg masses, II Effect of spacing, size and number of eggs on ventilation of masses of embryos in jelly, adherent groups, or thinwalled capsules. J Exp Mar Biol Ecol 84:85-93

Strathmann RR, Strathmann MF (1982) The relationship between adult size and brooding in marine invertebrates. Am Nat 119:91-101

Strathmann R, Strathmann M (1995) Oxygen supply and limits on aggregation of embryos. J Mar Biol Assoc UK 75: $413-428$

Sullivan CH, Maugel TK (1984) Formation, organization, and composition of the egg capsule of the marine gastropod Ilyanassa obsoleta. Biol Bull 167:378-389

Thiel M (1999) External parental care in marine amphipods, II Maternal protection of juveniles from predation. J Exp Mar Biol Ecol 234:235-253

Trivers RL (1972) Parental investment and sexual selection. In: Campbell B (ed) Sexual selection and the descent of man. Aldine Press, Chicago, IL, p 136-179

Wear RG (1974) Incubation in British decapod Crustacea, and the effects of temperature on the rate and success of embryonic development. J Mar Biol Assoc UK 54:745-762

Wheatly MG (1981) The provision of oxygen to developing eggs by female shore crabs (Carcinus maenas). J Mar Biol Assoc UK 61:117-128

Williams GC (1966) Natural selection, the cost of reproduction, and a refinement of Lack's principle. Am Nat 100: $687-690$

Submitted: December 30, 2007; Accepted: June 10, 2008

Proofs received from author(s): September 17, 2008 